\title{
Electronic Health Records vs Medicaid Claims: Completeness of Diabetes Preventive Care Data in Community Health Centers
}

\author{
Jennifer E. DeVoe, MD, DPbil ${ }^{1}$ \\ Rachel Gold, $\mathrm{PbD}, M P \mathrm{H}^{2}$ \\ Patti McIntire, BA:PPPM ${ }^{3}$ \\ Jon Puro, MPA-HA \\ Susan Chauvie, RN, MPA-HA \\ Charles A. Gallia, $P b D^{4}$
}

'Department of Family Medicine, Oregon Health and Science University, Portland, Oregon

${ }^{2}$ Kaiser Permanente Northwest Center for Health Research, Portland, Oregon

${ }^{3} \mathrm{OCHIN}$, Inc, Portland, Oregon

${ }^{4}$ Division of Medical Assistance Programs, Human Services Department, Salem, Oregon

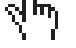

MORE ONLINE

www.annfammed.org
Conflicts of interest: authors report none.

\section{CORRESPONDING AUTHOR}

Jennifer E. DeVoe, MD, DPhil ${ }^{1}$

Department of Family Medicine

Oregon Health and Science University,

Mailcode: FM

3181 Sam Jackson Park Rd

Portland, OR 97239

devoej@ohsu.edu

\begin{abstract}
PURPOSE Electronic Health Record (EHR) databases in community health centers (CHCs) present new opportunities for quality improvement, comparative effectiveness, and health policy research. We aimed (1) to create individual-level linkages between EHR data from a network of CHCs and Medicaid claims from 2005 through 2007; (2) to examine congruence between these data sources; and (3) to identify sociodemographic characteristics associated with documentation of services in one data set vs the other.
\end{abstract}

METHODS We studied receipt of preventive services among established diabetic patients in 50 Oregon CHCs who had ever been enrolled in Medicaid $(\mathrm{N}=2,103)$. We determined which services were documented in EHR data vs in Medicaid claims data, and we described the sociodemographic characteristics associated with these documentation patterns.

RESULTS In 2007, the following services were documented in Medicaid claims but not the EHR: $11.6 \%$ of total cholesterol screenings received, $7.0 \%$ of total influenza vaccinations, $10.5 \%$ of nephropathy screenings, and $8.8 \%$ of tests for glycated hemoglobin $\left(\mathrm{HbA}_{1 \mathrm{c}}\right)$. In contrast, the following services were documented in the EHR but not in Medicaid claims: $49.3 \%$ of cholesterol screenings, $50.4 \%$ of influenza vaccinations, $50.1 \%$ of nephropathy screenings, and $48.4 \%$ of $\mathrm{HbA}_{1 \mathrm{c}}$ tests. Patients who were older, male, Spanish-speaking, above the federal poverty level, or who had discontinuous insurance were more likely to have services documented in the EHR but not in the Medicaid claims data.

CONCLUSIONS Networked EHRs provide new opportunities for obtaining more comprehensive data regarding health services received, especially among populations who are discontinuously insured. Relying solely on Medicaid claims data is likely to substantially underestimate the quality of care.

Ann Fam Med 2011;9:351-358. doi:10.1370/afm.1279.

\section{INTRODUCTION}

A $\mathrm{n}$ important part of most health care quality assessment efforts is measuring rates of receipt of recommended services. Health insurthese quality measures, assessing the performance of health care providers, and measuring geographic variation in care delivery and expenditures. ${ }^{1-4}$ Such administrative claims data, however, have long been known to contain incomplete information on care received..$^{5-8}$ Claims data are incomplete because not all services received are billed, patients change insurance payers, and a high percentage of US patients do not have stable insurance coverage and thus incur no claims when they receive care.

Community health centers (CHCs) provide services to such uninsured populations ${ }^{9-15}$; thus, their medical records include information about receipt of care that would not be captured in claims data. Until recently, 
however, studies of services received in CHCs have been limited to labor-intensive audits of paper medical records, or the collection of primary data from patient surveys. ${ }^{16-27}$ Electronic health record (EHR) databases have the potential to help researchers and policy makers overcome many of the previous limitations to measuring receipt of care in CHCs. Thus, these emergent data resources present new opportunities for measuring care quality in vulnerable populations, using automated EHR data available in real time.

To test the hypothesis that, in a CHC population, EHR data will portray outpatient care received more accurately than will Medicaid claims, we studied receipt of preventive care services among established diabetic patients from a linked CHC network. We created individual-level linkages between EHR data from 50 Oregon CHCs linked through the OCHIN Health Center-Controlled Network, and Medicaid insurance claims. We aimed (1) to examine congruence between these 2 data sources, and (2) to identify sociodemographic characteristics associated with documentation of services in EHR vs Medicaid claims data.

\section{METHODS}

\section{Setting: A Network of Community Health Centers in Oregon with Linked EHR Data} In 2001, a group of CHCs in Oregon formed a collaboration, originally called the Oregon Community Health Information Network and shortened to OCHIN as other states joined, to facilitate the adoption of health information technology in CHCs. These CHCs collectively purchased a centrally hosted Epic EHR system, and then instituted an enterprise-wide master patient index. OCHIN built and maintains this fully integrated electronic health information exchange system, in which each patient has a single medical record available to clinicians across the network. OCHIN's single database spans clinical, access, and revenue functions. As of December 1, 2010, OCHIN was supporting EHRs at more than 200 $\mathrm{CHC}$ sites serving more than 860,000 unique patients with more than 7.9 million visits since 2002 .

\section{Study Population and Data Linkages}

We selected adult patients who had at least 2 visits between January 1, 2004, and December 31, 2005, associated with a diabetes mellitus ICD-9 (International Classification of Diseases, Nintb Revision) diagnostic code and at least 1 visit for any reason in both 2006 and 2007 (diabetes ICD-9 codes: 250.x, 253.5, 357.2, 362.01-2, 366.41, 790.21-2, 790.29, 791.5-6, and V65.46). These criteria ensured a minimum level of continuity of care between 2004 and 2007 and reduced the likelihood of including patients who left the clinic network. OCHIN EHR data are limited before 2005, so 2004 data were used only to identify the study cohort; outcomes were assessed in 2005-2007 exclusively.

From 4,240 adult OCHIN patients with diabetes who met the initial inclusion criteria, we selected those with an Oregon Medicaid identification (ID) number $(\mathrm{N}=2,103)$. Medicaid is the primary insurer of this population. When a visit was not covered by Medicaid, more than $90 \%$ of this population reported having no other insurance. Using Medicaid ID numbers available in both data sets, we made individual-level linkages between OCHIN's EHR data and Oregon's Medicaid claims data. We obtained data-sharing agreements between all agencies and researchers involved in the study. The study protocol was approved by the institutional review boards of the Kaiser Permanente Center for Health Research and Oregon Health and Science University.

\section{Variables}

We focused on receipt of 4 evidence-based diabetes preventive care services: assessment of glycated hemoglobin $\left(\mathrm{HbA}_{1 \mathrm{c}}\right)$, lipid screening (low-density lipoprotein cholesterol [LDL]), influenza vaccination, and nephropathy screening (urine microalbumin). It is recommended that diabetic patients receive these services at least annually. ${ }^{28-33}$ We assessed 2 outcomes for each of these 4 measures: (1) whether a patient received the service in any year during the 2005 2007 period, and (2) whether a patient received the service in all 3 years, 2005 through 2007. Services were identified using procedure codes and CPT codes commonly associated with each (Supplemental Appendix, available at http://www.annfammed.org/ cgi/content/full/9/4/351/DC1). Although not an exhaustive list of codes, this list included all rel-

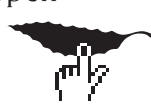
evant codes that were used in the OCHIN database as confirmed by OCHIN data architects.

\section{Analysis}

We first described the sociodemographic characteristics of the study population. For the remainder of the analyses, we assessed whether services were documented in 1 or both data sources, as illustrated in Figure 1, which included the following 6 possible combinations of data:

1. Medicaid insurance claims data (Figure 1, A+ab)

2. OCHIN clinic EHR data (Figure 1, B+ab)

3. A combined Medicaid claims-EHR data set (Figure 1, $\mathrm{A}+\mathrm{B}+\mathrm{ab}$ )

4. Only in Medicaid claims and not in EHR data (Figure 1, A)

5. Only in EHR data and not in Medicaid claims data (Figure 1B)

6. Both Medicaid claims and EHR data (Figure 1, ab) 


\section{Figure 1. Relationship between the 2 study data} sources.

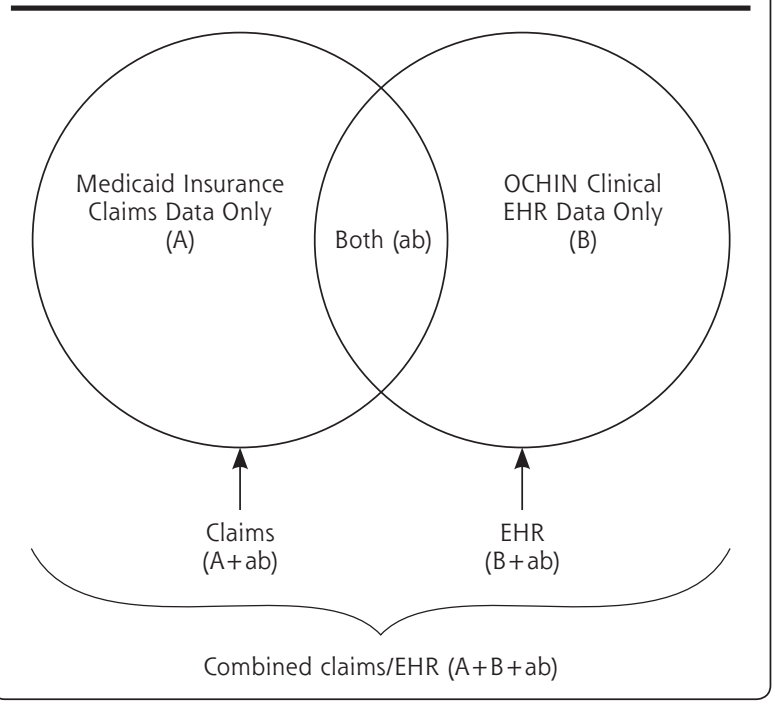

$21.5 \%$ were 65 years or older (Table 1). The population was $17.0 \%$ Hispanic and $9.5 \%$ black, and almost all were from households below $200 \%$ of the federal poverty level (FPL).

\section{Documentation in Medicaid Claims, EHR, and} a Combined Medicaid Claims-EHR Database

As displayed in Table 2, the optimal service reporting was obtained when combining the EHR and claims data [Figure $1(\mathrm{~A}+\mathrm{B}+\mathrm{ab})]$. When comparing service receipt rates in claims vs EHR data, the rates in EHR data (Figure 1, B $+\mathrm{ab}$ ) were consistently closer to the combined total than were those from the claims data (Figure 1, $\mathrm{A}+\mathrm{ab}$ ).

\section{Documentation in One Data Set vs Both Data Sets}

In almost all cases fewer than one-half of the patients who received services had documentation in both EHR and Medicaid claims data (Figure 1, ab) (Table 3). The
We compared the percentages of patients who had received the services of interest using only the claims data (Figure 1, A+ab), only the EHR data (Figure 1, B+ab), and the combined claims/EHR data set (Figure $1(A+B+a b)$. Then, among all patients who received at least 1 service over a specified time period (obtained from the combined data sets), we determined the percentage with service documentation only in Medicaid claims data (Figure 1, A), only in EHR data (Figure 1, B), or in both data sources (Figure 1, ab). Finally, to better characterize the population subgroups most likely to be missed in claims data (Figure $1, A+a b)$, we conducted a series of multivariate logistic regression models to identify sociodemographics significantly associated with having documentation in only the EHR data (Figure 1, B) and not in the claims data. All analyses were conducted using SAS 9.2 statistical software. ${ }^{34}$

\section{RESULTS}

The majority of patients were aged 19 to 64 years $(78.5 \%)$; only
Table 1. Demographic Characteristics of Established Adult Diabetic Patients in the OCHIN EHR Data Set With an Oregon Medicaid Identification Number $(\mathrm{N}=2,103)$

\begin{tabular}{|c|c|c|c|}
\hline Characteristic & $\begin{array}{l}\text { Study } \\
\text { Population } \\
\text { No. (\%) }\end{array}$ & Characteristic & $\begin{array}{c}\text { Study } \\
\text { Population } \\
\text { No. (\%) }\end{array}$ \\
\hline Age (as of January 1, 2005), y & \multicolumn{3}{|c|}{ Combined race/ethnicity ${ }^{b}$} \\
\hline $19-35$ & $179(8.5)$ & White & $1,276(60.7)$ \\
\hline $36-50$ & $605(28.8)$ & Hispanic & $358(17.0)$ \\
\hline $51-64$ & $866(41.2)$ & Black & $199(9.5)$ \\
\hline$\geq 65$ & $453(21.5)$ & Asian/Pacific Islander & $157(7.5)$ \\
\hline Sex & & American Indian/Alaska & $23(1.1)$ \\
\hline Female & $1,306(62.1)$ & Native & \\
\hline Male & 797 (37.9) & Unknown & $90(4.3)$ \\
\hline Primary language & & \multirow{2}{*}{\multicolumn{2}{|c|}{$\begin{array}{l}\text { Health insurance coverage } \\
\text { (Medicaid and OCHIN } \\
\text { coverage data combined) }\end{array}$}} \\
\hline English & $1,413(67.2)$ & & \\
\hline Spanish & $298(14.2)$ & Fully covered Jan 1 & $1,344(63.9)$ \\
\hline Russian & $127(6.0)$ & 2005-Dec 31, 2007 & \\
\hline Other & $207(9.8)$ & \multirow{2}{*}{$\begin{array}{l}\text { Not fully covered Jan 1, } \\
\text { 2005-Dec 31, } 2007\end{array}$} & \multirow[t]{2}{*}{$759(36.1)$} \\
\hline Unknown & $58(2.8)$ & & \\
\hline \multicolumn{4}{|l|}{ Household income as $\%$ of FPLa } \\
\hline $0 \%-49 \%$ & $748(35.6)$ & & \\
\hline $50 \%-99 \%$ & $967(46.0)$ & & \\
\hline $100 \%-149 \%$ & $266(12.6)$ & & \\
\hline $150 \%-199 \%$ & $29(1.4)$ & & \\
\hline $200 \%+$ & $39(1.9)$ & & \\
\hline Unknown & $53(2.5)$ & & \\
\hline
\end{tabular}

$E H R=$ electronic health record; $F P L=$ federal poverty level; ID = identification.

Note: From OCHIN, unless otherwise specified; data sources: OCHIN EHR and Oregon Medicaid claims data.

a Approximately $9 \%$ of total visits was missing FPL information, including $<2 \%$ of visits with FPL recorded as $>1,000 \%$. Average household income for study population $(n=4,240)$ was $81.2 \%$ of $F P L$; the subset with Medicaid ID number $(n=2,103)$ was $65.0 \%$ of FPL.

${ }^{b}$ Race/ethnicity was determined by data from OCHIN clinic visits; a person who was ever classified as Hispanic or had Spanish as their primary language was considered Hispanic. A person ever classified as black, Asian, etc, was classified as such. Data was collected by the Medicaid office as a combined variable. 
Table 2. Receipt of Diabetes Preventive Services Documented in Medicaid Claims Data, OCHIN EHR Data, and Combined Medicaid Claims-EHR Data Set Among OCHIN Diabetic Patients With a Medicaid Identification Number $(\mathrm{N}=2,103)$

\begin{tabular}{|c|c|c|c|c|}
\hline Preventive Service & Period & $\begin{array}{c}\text { Claims Data Only } \\
\text { No. (\%) }\end{array}$ & $\begin{array}{c}\text { EHR Data Only }{ }^{b} \\
\text { No. (\%) }\end{array}$ & $\begin{array}{c}\text { Combined Datac } \\
\text { No. (\%) }\end{array}$ \\
\hline \multirow[t]{4}{*}{$\geq 1$ LDL screen } & $2005-2007$ & $1,196(56.9)$ & $1,588(75.5)$ & $1836(87.3)$ \\
\hline & 2005 only & $841(40.0)$ & $1,034(49.2)$ & $1,345(64.0)$ \\
\hline & 2006 only & $756(35.9)$ & $1,128(53.6)$ & $1,343(63.9)$ \\
\hline & 2007 only & $684(32.5)$ & $1,191(56.6)$ & $1,348(64.1)$ \\
\hline \multirow[t]{4}{*}{$\geq 1$ Influenza vaccination } & $2005-2007$ & $1,083(51.5)$ & $1,486(70.7)$ & $1,517(72.1)$ \\
\hline & 2005 only & $415(19.7)$ & $990(47.1)$ & $1,016(48.3)$ \\
\hline & 2006 only & $486(23.1)$ & $895(42.6)$ & $947(45.0)$ \\
\hline & 2007 only & $478(22.7)$ & $897(42.7)$ & $964(45.8)$ \\
\hline \multirow[t]{4}{*}{$\geq 1$ Microalbumin screen } & $2005-2007$ & $872(41.5)$ & $1,364(64.9)$ & $1,517(72.1)$ \\
\hline & 2005 only & $524(24.9)$ & 764 (36.3) & $920(43.7)$ \\
\hline & 2006 only & $507(24.1)$ & $810(38.5)$ & $942(44.8)$ \\
\hline & 2007 only & $472(22.4)$ & $847(40.3)$ & $946(45.0)$ \\
\hline \multirow[t]{4}{*}{$\geq 1 \mathrm{HbA}_{1 \mathrm{c}}$} & $2005-2007$ & $1,374(65.3)$ & $1,905(90.6)$ & $2,025(96.3)$ \\
\hline & 2005 only & $984(46.8)$ & $1,422(67.6)$ & $1,652(78.6)$ \\
\hline & 2006 only & $1,005(47.8)$ & $1,537(73.1)$ & $1,714(81.5)$ \\
\hline & 2007 only & $876(41.7)$ & $1,550(73.7)$ & 1,699 (80.8) \\
\hline \multicolumn{5}{|c|}{$\mathrm{EHR}=$ electronic health record; $\mathrm{HbA}_{\mathrm{Ic}}=$ glycated hemoglobin; $\mathrm{LDL}=$ low-density lipoprotein cholesterol. } \\
\hline \multicolumn{5}{|c|}{$\begin{array}{l}\text { a Figure } 1, A+a b \\
\text { ' Figure } 1, B+a b \\
\text { ' Figure } 1, A+B+a b\end{array}$} \\
\hline \multicolumn{5}{|c|}{ Data sources: OCHIN electronic health records (EHR) and Oregon Medicaid claims data. } \\
\hline
\end{tabular}

\section{Table 3. Percentage of Diabetic Patients Who Received Services as Reported in OCHIN EHR Only,} Medicaid Claims Data Only, or Combined EHR and Medicaid Claims Data Set

\begin{tabular}{|c|c|c|c|c|c|}
\hline \multirow[b]{2}{*}{ Preventive Service } & \multirow[b]{2}{*}{ Period } & \multirow{2}{*}{$\begin{array}{c}\geq 1 \text { Service Received } \\
\text { Combined Data }{ }^{a} \\
\text { Total No. }\end{array}$} & \multicolumn{3}{|c|}{ Documented $\geq 1$ Service Received } \\
\hline & & & $\begin{array}{l}\text { Claims Datab } \\
\text { No. (\%) }\end{array}$ & $\begin{array}{c}\text { EHR Datac } \\
\text { No. }(\%)\end{array}$ & $\begin{array}{c}\text { Combined Datad } \\
\text { No. (\%) }\end{array}$ \\
\hline \multirow[t]{4}{*}{$\geq 1$ LDL screen } & 2005-2007 & 1,836 & $248(13.5)$ & $640(34.9)$ & $948(51.6)$ \\
\hline & 2005 only & 1,345 & $311(23.1)$ & $504(37.5)$ & $530(39.4)$ \\
\hline & 2006 only & 1,343 & $215(16.0)$ & $587(43.7)$ & $541(40.3)$ \\
\hline & 2007 only & 1,348 & $157(11.6)$ & $664(49.3)$ & $527(39.1)$ \\
\hline \multirow[t]{4}{*}{$\geq 1$ Influenza vaccination } & 2005-2007 & 1,517 & $31(2.0)$ & $689(45.2)$ & $797(52.5)$ \\
\hline & 2005 only & 1,016 & $26(2.6)$ & $601(59.2)$ & $389(38.3)$ \\
\hline & 2006 only & 947 & $52(5.5)$ & $461(48.7)$ & $434(45.8)$ \\
\hline & 2007 only & 964 & $67(7.0)$ & $486(50.4)$ & $411(42.6)$ \\
\hline \multirow[t]{4}{*}{$\geq 1$ Microalbumin screen } & $2005-2007$ & 1,517 & $153(10.1)$ & $645(42.5)$ & 719 (47.4) \\
\hline & 2005 only & 920 & $156(17.0)$ & $396(43.0)$ & $368(40.0)$ \\
\hline & 2006 only & 942 & $132(14.0)$ & $435(46.2)$ & 375 (39.8) \\
\hline & 2007 only & 946 & 99 (10.5) & $474(50.1)$ & 373 (39.4) \\
\hline \multirow[t]{4}{*}{$\geq 1 \mathrm{HbA}_{\mathrm{lc}}$ screen } & 2005-2007 & 2,025 & $120(5.9)$ & $651(32.1)$ & $1,254(61.9)$ \\
\hline & 2005 only & 1,652 & $230(13.9)$ & 668 (40.4) & 754 (45.6) \\
\hline & 2006 only & 1,714 & $177(10.3)$ & 709 (41.4) & $828(48.3)$ \\
\hline & 2007 only & 1,699 & $149(8.8)$ & 823 (48.4) & 727 (42.8) \\
\hline \multicolumn{6}{|c|}{$\mathrm{EHR}=$ electronic health record; $\mathrm{HbA}_{\mathrm{lc}}=$ glycated hemoglobin; $\mathrm{LDL}=$ low-density lipoprotein cholesterol. } \\
\hline \multicolumn{6}{|c|}{ Note: Data sources: OCHIN EHR and Oregon Medicaid claims data. Row percentages approximately $=100 \%$ (rounded). } \\
\hline \multicolumn{6}{|c|}{ a Figure $1, A+B+a b$} \\
\hline \multicolumn{6}{|l|}{${ }^{\mathrm{b}}$ Figure $1, \mathrm{~A}$. } \\
\hline \multicolumn{6}{|l|}{ ' Figure 1, B. } \\
\hline${ }^{\mathrm{d}}$ Figure 1, ab. & & & & & \\
\hline
\end{tabular}




\begin{tabular}{|c|c|c|c|c|}
\hline Characteristic & $\begin{array}{c}\geq 1 \text { LDL Screen } \\
(n=1,836) \\
\text { AOR }(95 \% \mathrm{Cl})\end{array}$ & $\begin{array}{l}\geq 1 \text { Influenza } \\
\text { Vaccination } \\
(n=1,517) \\
\text { AOR }(95 \% \mathrm{Cl})\end{array}$ & $\begin{array}{c}\geq 1 \text { Microalbumin } \\
\text { Screen } \\
(n=1,517) \\
\text { AOR }(95 \% \mathrm{Cl})\end{array}$ & $\begin{array}{c}\geq 1 \mathrm{HbA}_{1 \mathrm{c}} \text { Screen } \\
(\mathrm{n}=2,025) \\
\text { AOR }(95 \% \mathrm{Cl})\end{array}$ \\
\hline \multicolumn{5}{|c|}{ Age (as of January 1, 2005), y } \\
\hline 19 to 35 & 1.00 & 1.00 & 1.00 & 1.00 \\
\hline 36 to 50 & $0.95(0.63-1.44)$ & $1.06(0.68-1.65)$ & $1.17(0.76-1.80)$ & $1.22(0.81-1.83)$ \\
\hline 51 to 64 & $0.97(0.65-1.44)$ & $1.12(0.73-1.73)$ & $1.24(0.81-1.89)$ & $1.18(0.79-1.75)$ \\
\hline$\geq 65$ & $5.54(3.52-8.73)^{a}$ & $4.10(2.52-6.68)^{a}$ & $12.89(7.62-21.81)^{\mathrm{a}}$ & $6.61(4.22-10.34)^{\mathrm{a}}$ \\
\hline \multicolumn{5}{|l|}{ Sex } \\
\hline Female & 1.00 & 1.00 & 1.00 & 1.00 \\
\hline Male & $1.33(1.08-1.65)^{a}$ & $1.21(0.97-1.52)$ & $1.38(1.09-1.73)^{a}$ & $1.28(1.03-1.57)^{a}$ \\
\hline \multicolumn{5}{|l|}{ Primary language } \\
\hline English & 1.00 & 1.00 & 1.00 & 1.00 \\
\hline Spanish & $3.90(1.86-8.17)^{\mathrm{a}}$ & $1.66(0.84-3.27)$ & $4.24(1.83-9.81)^{\mathrm{a}}$ & $2.50(1.32-4.73)^{a}$ \\
\hline Other & $0.91(0.66-1.26)$ & $1.38(0.97-1.95)$ & $0.53(0.37-0.76)^{\mathrm{a}}$ & $1.00(0.73-1.38)$ \\
\hline Unknown & $1.88(1.00-3.53)$ & $4.74(2.22-10.11)^{\mathrm{a}}$ & $1.52(0.74-3.13)$ & $1.36(0.72-2.55)$ \\
\hline \multicolumn{5}{|c|}{ Household income, as percent of FPL } \\
\hline$\geq 100 \%$ & 1.00 & 1.00 & 1.00 & 1.00 \\
\hline $0 \%-99 \%$ & $0.70(0.53-0.92)^{\mathrm{a}}$ & $0.64(0.48-0.86)^{\mathrm{a}}$ & $0.71(0.52-0.97)^{\mathrm{a}}$ & $0.75(0.57-0.98)^{a}$ \\
\hline Unknown & $0.35(0.15-0.79)^{a}$ & $0.24(0.10-0.57)^{a}$ & $0.14(0.04-0.43)^{\mathrm{a}}$ & $0.38(0.18-0.81)^{a}$ \\
\hline \multicolumn{5}{|c|}{ Combined race/ethnicity } \\
\hline White & 1.00 & 1.00 & 1.00 & 1.00 \\
\hline Hispanic & $0.65(0.32-1.32)$ & $1.36(0.72-2.54)$ & $0.48(0.22-1.07)$ & $0.98(0.54-1.80)$ \\
\hline Other & $0.87(0.66-1.16)$ & $0.74(0.55-1.00)$ & $1.36(1.02-1.82)^{a}$ & $0.83(0.63-1.11)$ \\
\hline Unknown & $0.79(0.47-1.34)$ & $0.64(0.36-1.15)$ & $1.02(0.60-1.74)$ & $0.52(0.29-0.94)^{a}$ \\
\hline \multicolumn{5}{|c|}{ Health insurance coverage (2005-2007) } \\
\hline Full coverage & 1.00 & 1.00 & 1.00 & 1.00 \\
\hline Not full coverage & $1.69(1.33-2.14)^{a}$ & $2.62(2.04-3.36)^{\mathrm{a}}$ & $1.80(1.40-2.32)^{\mathrm{a}}$ & $2.22(1.77-2.80)^{\mathrm{a}}$ \\
\hline
\end{tabular}

percentage of patients with documented receipt of service(s) in EHR only (Figure 1, B) was consistently higher than in claims only (Figure 1, A). For example, in $2007,7.0 \%$ of patients had an influenza vaccination documented in claims only vs $50.4 \%$ in EHR only; the remaining $42.6 \%$ were documented in both data sets. For patients who received at least 1 microalbumin test to screen for nephropathy in 2007, $10.5 \%$ were documented in claims data but not in EHR, compared with $50.1 \%$ in EHR data but not in claims data, with the remaining $39.4 \%$ in both data sets.

Table 4 further shows that using Medicaid claims data (Figure 1, $\mathrm{A}+\mathrm{ab}$ ) to measure preventive services delivered in the OCHIN clinic network would result in underreporting, with greater disparities in certain sociodemographic subgroups. Patients older than 64 years, men, Spanish-speaking patients, and those without continuous Medicaid coverage throughout the study period had higher odds of service documentation in the EHR data only (Figure 1, B). Patients with incomes below the poverty level had lower odds of having data in the EHR only. There were few statistically significant differences associated with race/ ethnicity.

\section{DISCUSSION}

As expected, the combined EHR and Medicaid claims data provided the most complete picture of diabetes services received, and the EHR data provided a more complete picture than did data from Medicaid claims. This finding suggests that assessing performance in $\mathrm{CHC}$ based on Medicaid claims alone would be inaccurate, especially in certain subpopulations (Table 4). These disparities may occur because some subgroups have a more difficult time maintaining Medicaid cover- 
age. In some cases, these patients might be more likely to have more than 1 form of insurance coverage.

Data were missing from the Medicaid claims data for a large percentage of services received in an OCHIN-affiliated CHC. Although all patients in this study population had a Medicaid ID number, many had an insurance coverage gap during the study period; services received during a coverage gap were missed in claims data. Even some patients with continuous Medicaid coverage had services not documented in claims data. It is possible that these services were billed to a different insurer, especially for older patients with dual Medicare and Medicaid coverage. The most likely explanation for services documented in Medicaid claims but not in EHR data is that the service was received at a health care facility outside the OCHIN network and thus not documented in the OCHIN EHR, but billed to Medicaid.

Performance measures should optimally be measured using the most complete combination of data possible. When only one data set can be used, it should be EHR data. Although a relatively small percentage of services were missing in the EHR data, it was reassuring that for 3 of 4 outcomes measured (Table 2), the EHR data moved closer to the combined data set rates with time (from 2005 to 2007), suggesting that EHR data are becoming more complete as systems mature. This finding also suggests a fairly reliable population denominator in the OCHIN clinic network's EHR data set.

\section{Research and Policy Implications}

Previous work has shown the relevance of $\mathrm{CHC}$ data to policy discussions about how to improve health care delivery and outcomes for underserved patients. ${ }^{9} 10,14,16,18,23,35,36$ Our findings show how EHR data from $\mathrm{CHC}$ networks provide a new resource for policy makers to better understand health services delivery in CHC populations. ${ }^{10,15,16,37-40}$ Policy makers and payers need to look beyond Medicaid claims data to measure population health and $\mathrm{CHC}$ quality performance. EHR databases — such as the one being built and maintained by OCHIN_will be key to the study of how health reform policies implemented under the Patient Protection and Affordable Care Act of 2010 (PPACA) affect the uninsured and underinsured. ${ }^{41-49}$ Although some states are putting considerable resources toward building all-payer claims databases to better address the PPACA's evaluation requirements, ${ }^{50}$ such databases will not include uninsured and transiently insured populations. Information from EHR data will be more accurate than administrative claims data; thus, it is imperative to further develop and validate important EHR data resources and to evaluate the extent to which EHR data can be used to supplement (or substitute for) claims data. Our results also show the potential usefulness of combining EHR and claims data sources for use in comparative effectiveness and translational research.

\section{Practice Implications}

In addition to the research and policy implications, our results have important implications for clinical practice. This study shows that a well-built EHR with comprehensive data can be more complete than claims data for measuring how a practice is performing. Clinicians can partner with researchers to study data from their own EHRs in the evaluation of quality improvement interventions and to measure the impact of these efforts on care delivery and outcomes.

\section{Limitations}

We only compared the OCHIN EHR data with Oregon Medicaid claims data, as Medicaid is the primary insurer of this population of patients. The analyses could be strengthened by linking EHR data with claims from additional payers. It was beyond the scope of these analyses to determine where patients had received care outside the OCHIN network. For example, this population's low rate of influenza vaccination is likely because many patients sought vaccinations outside the CHC system. Further research could identify external sites commonly used by this population and pursue methods to capture that data in the future.

Our results may give conservative estimates of the diabetic patient population in these clinics. We defined patients as diabetic if they had 2 or more visits associated with a diabetes diagnostic code over a 2-year time period, so we could avoid incorrectly considering patients as diabetic based on a single rule-out diagnostic code. This method is commonly used for the Healthcare Effectiveness Data and Information Set (HEDIS) measures. We further limited our population to ensure a continuity relationship. Thus, we likely missed some diabetic patients who had fewer than the minimum number of visits during the study period. Although our rates are comparable to available estimates from nationally representative data, ${ }^{16}$ directly comparing rates of receipt of care measures with those of other populations was not feasible, as previous assessments varied in how receipt of care was measured and how populations were defined. ${ }^{14-17,23,38,51}$ This analysis was done in one state, but it could be replicated in other states with similar CHC networks.

Despite the above limitations and the need for further study, we believe that OCHIN's data set is unique and substantially improves on what has been previously available. This study would not have been possible using older methods of paper chart review, data-sifting, and less-comprehensive data sets. 
Networked EHRs from CHCs provide new opportunities for obtaining more comprehensive data on health services received, especially in discontinuously insured populations. These EHR databases can be linked and compared with claims databases, such as Medicaid, and may prove to contain more robust data for the measurement of primary and preventive care services utilization in vulnerable populations. Relying solely on claims data is likely to substantially underestimate the quality of care received. Further, our study shows how primary care practices can collaborate within information technology networks and effectively partner with researchers to study their own care delivery, to conduct comparative effectiveness research, to affect the translation of evidence into practice, and to inform policies.

\section{To read or post commentaries in response to this article, see it online at http://www.annfammed.org/cgi/content/full/9/4/351.}

Submitted November 10, 2010; submitted, revised March 22, 2011; accepted April 11, 2011.

Key words: Electronic health records; access to health care; community health centers; primary health care; preventive health services; diabetes mellitus; medically uninsured; Medicaid

Author contributions: All authors take responsibility for the entire content of the manuscript. Drs DeVoe and Gold had full access to all of the data in the study and take responsibility for the integrity of the data and the accuracy of the data analysis. Drs DeVoe and Gold designed the analyses and wrote the manuscript. Ms McIntire and Mr Puro conducted data linkages and created the analysis data set. Dr Gold conducted all analyses. Ms Chauvie and Dr Gallia provided substantial consultation in study design and results interpretation.

Funding support: This study was supported by grant number UB2HA20235 from the Health Resources and Services Administration (HRSA), grant number 1RC4LM010852 from the National Library of Medicine, National Institutes of Health (NIH), and a small pilot grant from the Oregon Clinical and Translational Research Institute (OCTRI), grant number UL1 RR024140 01 from the National Center for Research Resources (NCRR), a component of the NIH, and NIH Roadmap for Medical Research (Gold and McIntire), and received support from the OHSU Department of Family Medicine Research Division (DeVoe). Dr DeVoe's time on this project was also supported by grant number 1K08HS16181 from the Agency for Healthcare Research and Quality (AHRQ). These funding agencies had no involvement in the design and conduct of the study; analysis, and interpretation of the data; and preparation, review, or approval of the manuscript. Ms Chauvie and Mr Puro's time was donated by OCHIN. Dr Gallia's time was donated by the Oregon Division of Medical Assistance Programs.

Acknowledgements: We are grateful to OCHIN and to the Oregon Division of Medical Assistance Programs. We also wish to acknowledge the contributions of reviewers and editors who made this manuscript significantly better.

\section{References}

1. Crystal S, Akincigil A, Bilder S, Walkup JT. Studying prescription drug use and outcomes with medicaid claims data: strengths, limitations, and strategies. Med Care. 2007;45(10)(Suppl 2):S58-S65.
2. Mitchell JB, Bubolz T, Paul JE, et al. Using Medicare claims for outcomes research. Med Care. 1994;32(7)(Suppl):JS38-JS51.

3. Wennberg JE, Fisher ES, Stukel TA, Sharp SM. Use of Medicare claims data to monitor provider-specific performance among patients with severe chronic illness. Health Aff (Millwood). 2004;Suppl Variation(Suppl Web Exclusives):VAR5-VAR18.

4. Baron JA, Lu-Yao G, Barrett J, McLerran D, Fisher ES. Internal validation of Medicare claims data. Epidemiology. 1994;5(5):541-544.

5. Fisher ES, Whaley FS, Krushat WM, et al. The accuracy of Medicare's hospital claims data: progress has been made, but problems remain. Am J Public Health. 1992;82(2):243-248.

6. Lohr KN. Use of insurance claims data in measuring quality of care. Int J Technol Assess Health Care. 1990;6(2):263-271.

7. Jollis JG, Ancukiewicz M, DeLong ER, Pryor DB, Muhlbaier LH, Mark DB. Discordance of databases designed for claims payment versus clinical information systems. Implications for outcomes research. Ann Intern Med. 1993;119(8):844-850.

8. lezzoni LI. Assessing quality using administrative data. Ann Intern Med. 1997;127(8 Pt 2):666-674.

9. O'Malley AS, Forrest CB, Politzer RM, Wulu JT, Shi L. Health center trends, 1994-2001: what do they portend for the federal growth initiative? Health Aff (Millwood). 2005;24(2):465-472.

10. Dievler A, Giovannini T. Community health centers: promise and performance. Med Care Res Rev. 1998;55(4):405-431.

11. National Healthcare Disparities Report, 2005. http://www.ahrq.gov Iqual/nhdr05/nhdr05.htm. 2008. Accessed Jul 19, 2010

12. Smedley BD, Stith AY, Nelson AR. Unequal Treatment: Confronting Racial and Ethnic Disparities in Health Care. Washington, DC: National Academy Press; 2005.

13. National Association of Community Health Centers. The Safety Net on the Edge. Bethesda, MD: NACHC; 2008.

14. Hicks LS, O'Malley AJ, Lieu TA, et al. The quality of chronic disease care in U.S. community health centers. Health Aff (Millwood). 2006;25(6):1712-1723.

15. Ferrer RL. Pursuing equity: contact with primary care and specialist clinicians by demographics, insurance, and health status. Ann Fam Med. 2007;5(6):492-502.

16. Landon BE, Hicks LS, O'Malley AJ, et al. Improving the management of chronic disease at community health centers. $N$ Engl J Med. 2007;356(9):921-934.

17. Nelson KM, Chapko MK, Reiber G, Boyko EJ. The association between health insurance coverage and diabetes care; data from the 2000 Behavioral Risk Factor Surveillance System. Health Serv Res. 2005;40(2):361-372.

18. Maizlish NA, Shaw B, Hendry K. Glycemic control in diabetic patients served by community health centers. Am J Med Qual. 2004;19(4):172-179.

19. Oladele $C R$, Barnett $E$. Racial/ethnic and social class differences in preventive care practices among persons with diabetes. BMC Public Health. 2006:6:259.

20. Gregg EW, Geiss LS, Saaddine J, et al. Use of diabetes preventive care and complications risk in two African-American communities. Am J Prev Med. 2001;21(3):197-202.

21. Beckles GLA, Engelgau MM, Narayan KMV, Herman WH, Aubert RE, Williamson DF. Population-based assessment of the level of care among adults with diabetes in the U.S. Diabetes Care. 1998;21(9):1432-1438.

22. Harris MI, Cowie CC, Eastman R. Health-insurance coverage for adults with diabetes in the U.S. population. Diabetes Care. 1994; 17(6):585-591.

23. Srinivasan M, Przybylski M, Swigonski N. The Oregon Health Plan: predictors of office-based diabetic quality of care. Diabetes Care. 2001;24(2):262-267. 
24. DeVoe JE, Petering R, Krois L. A usual source of care: supplement or substitute for health insurance among low-income children? Med Care. 2008;46(10):1041-1048.

25. Allred NJ, Wooten KG, Kong Y. The association of health insurance and continuous primary care in the medical home on vaccination coverage for 19- to 35-month-old children. Pediatrics. 2007;119(Suppl 1):S4-S11

26. DeVoe JE, Baez A, Angier H, Krois L, Edlund C, Carney PA. Insurance + access not equal to health care: typology of barriers to health care access for low-income families. Ann Fam Med. 2007; 5(6):511-518.

27. Carlson MJ, DeVoe J, Wright BJ. Short-term impacts of coverage loss in a Medicaid population: early results from a prospective cohort study of the Oregon Health Plan. Ann Fam Med. 2006;4(5):391-398.

28. American Diabetes Association. Standards of medical care in diabetes-2010. Diabetes Care. 2010;33(Suppl 1):S11-S61.

29. American Diabetes Association. Standards of medical care in diabetes-2008. Diabetes Care. 2008;31(Suppl 1):S12-S54.

30. American Diabetes Association. Standards of medical care in diabetes. Diabetes Care. 2004;27(Suppl 1):S15-S35.

31. Centers for Disease Control and Prevention (CDC). Preventive-care practices among persons with diabetes-United States, 1995 and 2001. MMWR Morb Mortal Wkly Rep. 2002;51(43):965-969.

32. US Department of Health \& Human Services (DHHS). Healthy People 2010. 2nd ed. Washington, DC: US Government Printing Office; 2000.

33. Fleming BB, Greenfield S, Engelgau MM, Pogach LM, Clauser SB, Parrott MA. The Diabetes Quality Improvement Project: moving science into health policy to gain an edge on the diabetes epidemic. Diabetes Care. 2001;24(10):1815-1820.

34. SAS Institute. What's New in SAS 9.0, 9.1,9.1.2, and 9.1.3. Cary, NC: SAS Institute, Inc; 2004

35. Porterfield DS, Kinsinger L. Quality of care for uninsured patients with diabetes in a rural area. Diabetes Care. 2002;25(2):319-323.

36. Fenton JJ, Von Korff M, Lin EH, Ciechanowski P, Young BA. Quality of preventive care for diabetes: effects of visit frequency and competing demands. Ann Fam Med. 2006;4(1):32-39.

37. Patient-Centered Primary Care Collaborative. Joint Principles of the Patient Centered Medical Home. http://www.pcpcc.net/node/14. 2007.

38. Stenger RJ, DeVoe JE. Policy challenges in building the medical home: do we have a shared blueprint? J Am Board Fam Med. 2010; 23(3):384-392.
39. Kellerman R, Kirk L. Principles of the patient-centered medical home. Am Fam Physician. 2007;76(6):774-775.

40. Rosenthal TC. The medical home: growing evidence to support a new approach to primary care. J Am Board Fam Med. 2008;21(5): 427-440.

41. Rahimi AR, Spertus JA, Reid KJ, Bernheim SM, Krumholz HM. Financial barriers to health care and outcomes after acute myocardial infarction. JAMA. 2007;297(10):1063-1072.

42. Halpern MT, Ward EM, Pavluck AL, Schrag NM, Bian J, Chen AY Association of insurance status and ethnicity with cancer stage at diagnosis for 12 cancer sites: a retrospective analysis. Lancet Oncol. 2008;9(3):222-231.

43. Hadley J. Insurance coverage, medical care use, and short-term health changes following an unintentional injury or the onset of a chronic condition. JAMA. 2007;297(10):1073-1084.

44. Haider AH, Chang DC, Efron DT, Haut ER, Crandall M, Cornwell EE III. Race and insurance status as risk factors for trauma mortality. Arch Surg. 2008;143(10):945-949.

45. DeVoe JE, Tillotson CJ, Wallace LS. Children's receipt of health care services and family health insurance patterns. Ann Fam Med. 2009;7(5):406-413.

46. Hiestand BC, Prall DM, Lindsell CJ, et al. Insurance status and the treatment of myocardial infarction at academic centers. Acad Emerg Med. 2004;11(4):343-348.

47. Fowler RA, Noyahr LA, Thornton JD, et al; American Thoracic Society Disparities in Healthcare Group. An official American Thoracic Society systematic review: the association between health insurance status and access, care delivery, and outcomes for patients who are critically ill. Am J Respir Crit Care Med. 2010;181(9):1003-1011.

48. Wilper A, Woolhandler S, Himmelstein D, Nardin R. Impact of insurance status on migraine care in the United States: a population-based study. Neurology. 2010;74(15):1178-1183.

49. Smolderen KG, Spertus JA, Nallamothu BK, et al. Health care insurance, financial concerns in accessing care, and delays to hospital presentation in acute myocardial infarction. JAMA. 2010;303(14): 1392-1400.

50. Love D, Custer W, Miller P. All-Payer Claims Databases: State Initiatives to Improve Health Care Transparency. Commonwealth Fund Publication 1439. Vol 99, 2010. The Commonwealth Fund.

51. Saaddine JB, Engelgau MM, Beckles GL, Gregg EW, Thompson TJ، Narayan KM. A diabetes report card for the United States: quality of care in the 1990s. Ann Intern Med. 2002;136(8):565-574. 